\title{
Severity of acidosis affects long-term survival in COPD patients with hypoxemia after intensive care unit discharge
}

This article was published in the following Dove Press journal: International Journal of COPD

\author{
Sinem Gungor \\ Feyza Kargin \\ Ilim Irmak \\ Fulya Ciyiltepe \\ Eylem Acartürk Tunçay \\ Pinar Atagun Guney \\ Emine Aksoy \\ Birsen Ocakli \\ Nalan Adiguzel \\ Zuhal Karakurt \\ Respiratory Intensive Care Unit \\ Clinic, Sureyyapasa Chest Diseases \\ and Thoracic Surgery Teaching and \\ Research Hospital, Istanbul, Turkey
}

Correspondence: Zuhal Karakurt University of Health Sciences,

Sureyyapasa Chest Diseases and Thoracic Surgery Education and Research Hospital, Site Mahallesi, Atay Caddesi, Soyak Kibele Evleri, No 43, CI Blok Daire, I5 Ümraniye 34760, Istanbul, Turkey Tel +905326466590

Email zuhalkarakurt@hotmail.com
Background: Patients admitted to the intensive care unit (ICU) with acute respiratory failure (ARF) due to COPD have high mortality and morbidity. Acidosis has several harmful effects on hemodynamics and metabolism, and the current knowledge regarding the relationship between respiratory acidosis severity on the short- and long-term survival of COPD patients is limited. We hypothesized that COPD patients with severe acidosis would have a poorer short- and long-term prognosis compared with COPD patients with mild-to-moderate acidosis.

Patients and methods: This retrospective observational cohort study was conducted in a level III respiratory ICU of a tertiary teaching hospital for chest diseases between December 1, 2013, and December 30, 2014. Subject characteristics, comorbidities, ICU parameters, duration of mechanical ventilation, length of ICU stay, ICU mortality, use of domiciliary noninvasive mechanical ventilation (NIMV) and long-term oxygen therapy (LTOT), and short- and longterm mortality were recorded. Patients were grouped according to their arterial blood gas $(\mathrm{ABG})$ values during ICU admission: severe acidotic $(\mathrm{pH} \leq 7.20)$ and mild-to-moderate acidotic ( $\mathrm{pH}$ 7.21-7.35). These groups were compared with the recorded data. The mortality predictors were analyzed by logistic regression test in the ICU and the Cox regression test for long-term mortality predictors.

Results: During the study period, a total of 312 COPD patients admitted to the ICU with ARF, $69(72.5 \%$ male $)$ in the severe acidosis group and $243(79 \%$ male $)$ in the mild-to-moderate acidosis group, were enrolled. Group demographics, comorbidities, duration of mechanical ventilation, and length of ICU stay were similar in the two groups. The severe acidosis group had a significantly higher rate of NIMV failure (60.7\% vs $40 \%)$ in the ICU. Mild-to-moderate acidotic COPD patients using LTOT had longer survival after ICU discharge than those without LTOT. On the other hand, severely acidotic COPD patients without LTOT showed shorter survival than those with LTOT. Kaplan-Meier cumulative survival analysis showed that the 28-day and 1-, 2-, and 3-year mortality rates were $12.2 \%, 36.2 \%, 52.6 \%, 63.3 \%$, respectively $(p=0.09)$. The Cox regression analyses showed that older age, $\mathrm{PaO}_{2} / \mathrm{FiO}_{2}<300 \mathrm{mmHg}$, and body mass index $\leq 20 \mathrm{~kg} / \mathrm{m}^{2}$ was associated with mortality of all patients after 3 years.

Conclusion: Severely acidotic COPD patients had a poorer short- and long-term prognosis compared with mild-to-moderate acidotic COPD patients if acute and chronic hypoxemia was predominant.

Keywords: COPD, long term oxygen therapy, non-invasive mechanical ventilation, mortality, acute respiratory failure

\section{Introduction}

Patients with acute exacerbation of COPD and who require admission to the intensive care unit (ICU) have high mortality and morbidity. Severe acidosis $(\mathrm{pH} \leq 7.20)$ causes 
myocardial depression, arrhythmias, a decrease in peripheral vascular resistance, weakness of respiratory muscle, and an increase in pro-inflammatory cytokines, apoptosis, and cachexia. ${ }^{1}$ The severity of acidosis has been shown to be associated with a poor prognosis in patients with hypercapnic COPD exacerbation. ${ }^{2,3}$

Noninvasive mechanical ventilation (NIMV), as a complement to optimal medical treatment, is the gold standard for the treatment of mild-to-moderate hypercapnic acute respiratory failure (ARF) in patients with COPD. ${ }^{4}$ However, in the case of severely acidotic ARF, NIMV failure rate is high, and it requires invasive mechanical ventilation (IMV) and is associated with increased morbidity and mortality. ${ }^{5}$ Comorbidities in COPD patients, such as diabetes mellitus, arrhythmias, cachexia, hypertension, and especially renal diseases, adversely affect prognosis. ${ }^{6-10}$

COPD patients with severe hypercapnic respiratory acidosis are known to have higher rates of ICU mortality; however, data on short- and long-term mortality rates following ICU discharge are limited.

We hypothesized that severely acidotic COPD patients $(\mathrm{pH} \leq 7.20)$ discharged from the ICU have poorer survival in both the short and long term compared with mild-to-moderate acidotic COPD patients $(\mathrm{pH}>7.20)$ due to organ dysfunction in the ICU. The primary objective of this study was to demonstrate differences between the severe acidotic respiratory failure group and the non-severe acidosis group in the hospital and with respect to short- and long-term survival of the patients after discharge. The secondary objective was to define the risk factors for predictors of long-term mortality in the study groups.

\section{Patients and methods}

This retrospective observational cohort study was conducted in a level III respiratory ICU of a tertiary teaching hospital for chest diseases from December 1, 2013, to December 30, 2014. As it is a teaching hospital for chest diseases, most patients treated in the ICU are COPD patients with ARF. The study was conducted in full accordance with local Good Clinical Practice guidelines and current legislations, while patients' signed informed consent was not obtained due to the retrospective nature of the study, and permission was obtained from the local ethics committee of Sureyyapasa Chest Disease and Thoracic Surgery Research Hospital (23.11.207/005) who waived the need for patient consent to review their medical files. The study was according to the Declaration of Helsinki. As informed consent from patients to review their medical records was not obtained, patients' data were de-identified.

\section{Patients}

During the study period, patients previously diagnosed with COPD by a pulmonary specialist and who were admitted to the ICU with ARF, either due to exacerbation of COPD or pneumonia, were included. The COPD diagnosis was established according to the international guidelines by a physician who evaluated airflow obstruction on spirometry, forced expiratory volume in $1 \mathrm{~s}\left(\mathrm{FEV}_{1}\right)$ of $70 \%$ predicted or less, and an $\mathrm{FEV}_{1}$ and forced vital capacity (FVC) ratio of $70 \%$ or less. ${ }^{4}$ Patients were stratified into two groups according to their arterial blood gas (ABG) $\mathrm{pH}$ values on the first day of admission to the ICU (severe acidosis group, $\mathrm{pH} \leq 7.20$; mild-to-moderate acidosis group, $\mathrm{pH} \geq 7.21,<7.35$ ). Patient enrollment criteria and stratification are summarized in a flowchart (Figure 1).

\section{Definitions}

"ARF" was defined as partial arterial oxygen pressure $\left(\mathrm{PaO}_{2}\right)<60 \mathrm{mmHg}$ on room air or $\mathrm{PaO}_{2}$ over the fraction of inspired oxygen $\left(\mathrm{PaO}_{2} / \mathrm{FiO}_{2}\right)<300$, partial carbon dioxide pressure $\left(\mathrm{PaCO}_{2}\right) \geq 45 \mathrm{mmHg}$, and $\mathrm{pH} \leq 7.35$. $^{11,12}$

Organ dysfunction was assessed using the sequential organ failure assessment (SOFA) score and the multiple organ dysfunction criteria of systemic inflammatory response syndrome (SIRS) which was defined in sepsis guidelines. ${ }^{13,14}$ For respiratory organ dysfunction, $\mathrm{PaO}_{2} / \mathrm{FiO}_{2}$ was used; a $\mathrm{PaO}_{2} / \mathrm{FiO}_{2}$ of $<300$ indicated respiratory organ dysfunction. A serum creatinine of $>2.0 \mathrm{mg} / \mathrm{dL}$ indicated renal organ dysfunction; a serum platelet count of $<100,000 \mu \mathrm{L}$ defined hematological organ dysfunction; unresponsiveness to fluid resuscitation and requiring inotropic agents to sustain mean arterial blood pressure (MAP) over $70 \mathrm{mmHg}$ was defined as hemodynamic instability; and a Glasgow Coma Scale (GCS) of $<11$ was accepted as neurological organ dysfunction.

Exacerbation of COPD was defined as an acute change in respiratory symptoms of the patient beyond normal variability and resulting in a change in therapy. ${ }^{4}$ The presence of all the Anthonisen et al's ${ }^{15}$ criteria, namely worsening of dyspnea, increased volume of pulmonary secretions, and increased purulence of respiratory secretions, defined as infectious pattern. Standard treatment for COPD exacerbation, including bronchodilators, systemic corticosteroids, and appropriate antibiotics, was given to all patients with COPD exacerbations. ${ }^{4}$

Pneumonia was defined as the presence of infiltration on a chest radiograph with an acute illness associated with a new cough, with or without sputum, pleuritic chest pain, dyspnea, fever or hypothermia, and altered breath sounds on auscultation or leukocytosis. ${ }^{16}$ 


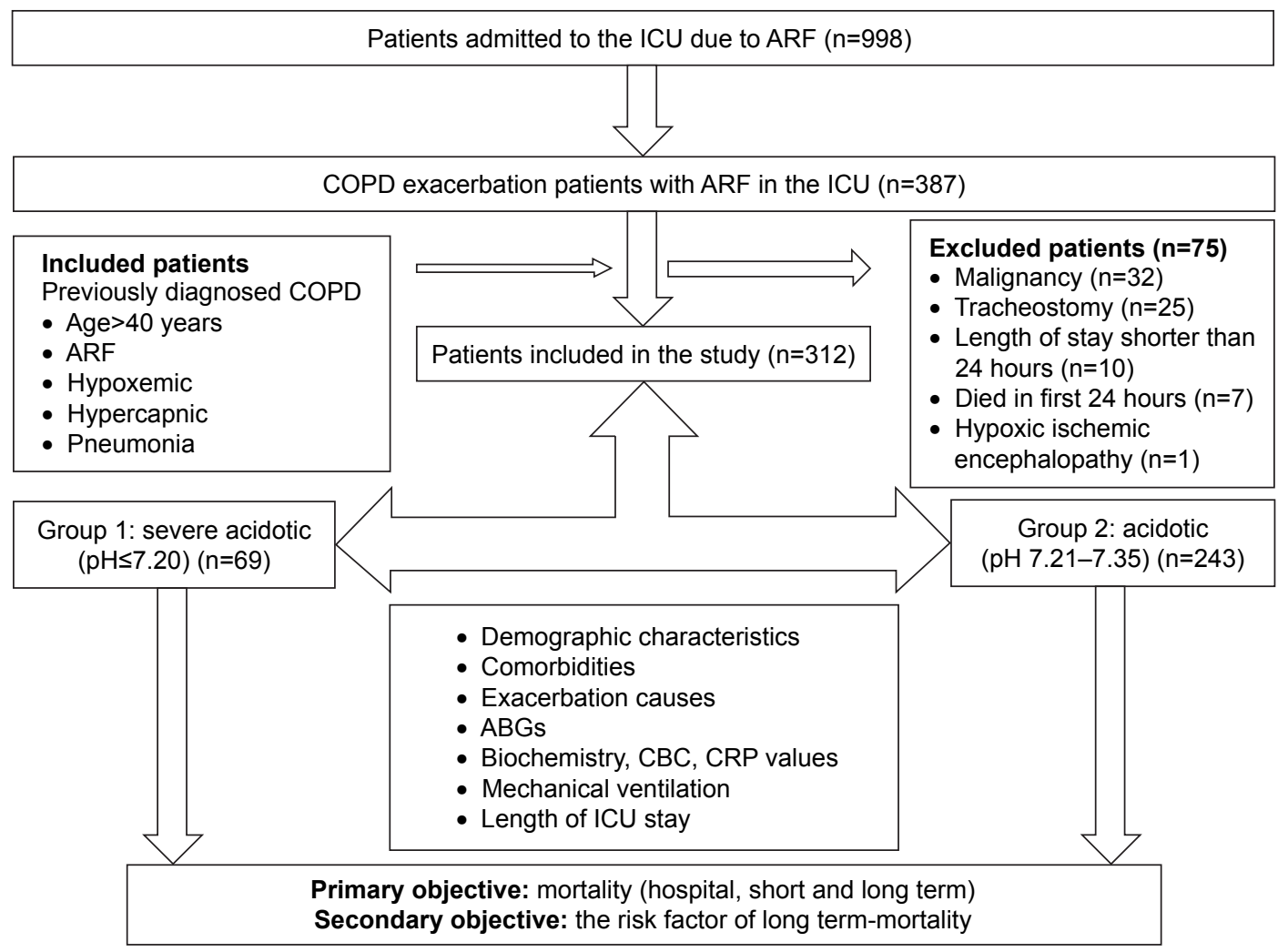

Figure I Flowchart of patient enrollment.

Abbreviations: ABG, arterial blood gas; ARF, acute respiratory failure; CBC, complete blood count; CRP, C-reactive protein; ICU, intensive care unit.

\section{Recorded data}

The data were collected electronically from the hospital database and patients' files. Patient demographics, comorbidities, acute physiology and chronic health evaluation (APACHE) II scores, ${ }^{17}$ smoking history, causes of exacerbation, ABGs, biochemistry, complete blood count (CBC), C-reactive protein (CRP) values, and use of IMV and NIMV were recorded. ICU mortality, 28-day mortality, and long-term mortality (36 months) were recorded from the government electronic mortality declaration system (www.obs.gov.tr).

\section{Mechanical ventilation}

Management of mechanical ventilation during the ICU stay was initiated based on a decision by the staff physician. Initially, NIMV was performed on all COPD patients with hypercapnic respiratory failure, unless contraindicated. ${ }^{12}$ NIMV was applied with ICU mechanical ventilators via a double-tube circuit with a full-face mask, intermittently for 1-3 hours, in the mode of pressure assist-control. If NIMV application was believed to be failing, IMV was applied in the pressure assist-control ventilation (PCV) mode and the ICU sedation protocol was applied. ${ }^{18,19}$ Invasively ventilated patients were extubated if treatment was considered to be successful after a 30-minute T-tube trial.

\section{Follow-up}

After ICU discharge, domiciliary NIMV was prescribed to COPD patients according to international guidelines. The criteria for long-term domiciliary NIMV were daytime hypercapnia with a $\mathrm{PaCO}_{2}$ of $\geq 55 \mathrm{mmHg}$ or a $\mathrm{PaCO}_{2}$ of $50-54 \mathrm{mmHg}$ and during the $\geq 2$ hours of nocturnal sleep oximetry if a decrease in oxygen saturation $\left(\mathrm{SpO}_{2}\right)$ of $88 \%$ for $\geq 5$ minutes was dectected. Long-term oxygen therapy (LTOT) was prescribed if the $\mathrm{PaO}_{2}$ was $<55 \mathrm{mmHg}$ or $\mathrm{SaO}_{2}$ was $\leq 88 \%$ in room air at the time of discharge from the ICU. It was also prescribed in clinically stable cases $\left(\mathrm{PaO}_{2} 55-60 \mathrm{mmHg}\right)$ if, after 3 weeks from discharge, there was evidence of pulmonary hypertension and peripheral edema or polycythemia (hematocrit $>55 \%) .{ }^{4}$ Appropriate medical therapy according to the Global Initiative for Chronic Obstructive Lung Diseases (GOLD) criteria was provided to all COPD patients at the time of discharge. ${ }^{4}$ Patients prescribed domiciliary NIMV and LTOT were followed up in the ICU outpatient clinic at 2-3-month intervals after discharge and evaluated for the efficiency of treatment and NIMV adherence.

\section{Statistical analyses}

Statistical analyses were performed using the portable SPSS version 20 (IBM Corporation, Armonk, NY, USA). 
Continuous variables are presented as mean \pm SD if normally distributed, and the Student's $t$-test was used for group comparisons. If the continuous variables were distributed non-normally, they are presented as the median with interquartile range $(25 \%-75 \%)$, and the study groups were compared using the Mann-Whitney $U$-test. The Pearson chi-squared test was used for dichotomous variables. We used the Pearson chi-square test for categorical variables (dichotomous variables). For ICU mortality risk factor analysis, the logistic regression test was used according to parameters included in the model. Kaplan-Meier survival curves were performed for patients with/without LTOT and further stratified according to the presence of severe and nonsevere acidosis. The Cox regression test was used to analyze long-term mortality risk factors and hazard ratios (HRs) with a $95 \%$ CI. A $p$-value of $<0.05$ was considered statistically significant.

\section{Results}

During the study period, 998 patients were admitted to the ICU and 387 (38.8\%) COPD patients were enrolled in the study. Details of the excluded patients are shown in Figure 1.
Among the 387 COPD patients, 312 eligible patients were included: 69 (22.1\%) in the severe acidosis group and 243 $(77.9 \%)$ in the mild-to-moderate acidosis group. All patients were followed up for at least 3 years after ICU discharge. Cumulative mortality of patients after ICU discharge was as follows: 28-day and 1-, 2-, 3-year mortality was $12.2 \%$ $(n=32), 36.2 \%(n=95), 52.6 \% \quad(n=138), 63.3 \% \quad(n=166)$, respectively.

Table 1 summarizes the demographics of the groups as well as the long-term home device usage and comorbidities. Both groups had similar age, gender dispersion, and smoking history, including biomass exposure. LTOT use was significantly higher in the mild-to-moderate acidosis group. Severely acidotic patients had a statistically higher rate of chronic renal failure (Table 1).

Among patients with chronic renal diseases $(n=6)$, four of them were in the severe acidosis group and none of them required renal dialysis. Of the patients who required dialysis $(n=6)$, only one had chronic renal failure.

Table 2 summarizes ICU data including the reasons for ICU admission, laboratory values on the first day in the ICU, ABG values on the day of ICU admission, length of

Table I Demographic characteristics and comorbidities of the study groups

\begin{tabular}{|c|c|c|c|}
\hline Characteristics & $\begin{array}{l}\text { Severe } \\
\text { acidosis group } \\
(\mathrm{N}=69)\end{array}$ & $\begin{array}{l}\text { Mild-to-moderate } \\
\text { acidosis group } \\
(\mathbf{N}=\mathbf{2 4 3})\end{array}$ & $p$-value \\
\hline Age, years, mean $( \pm S D)$ & $69 \pm 9$ & $68 \pm 10$ & 0.47 \\
\hline Gender, male, n (\%) & $50(72.5)$ & $192(79)$ & 0.25 \\
\hline $\mathrm{BMI}, \mathrm{kg} / \mathrm{m}^{2}$, mean $( \pm \mathrm{SD})$ & $23 \pm 6$ & $24 \pm 6$ & 0.025 \\
\hline No smoke exposure, $\mathrm{n}(\%)$ & $10(14.5)$ & $36(14.9)$ & 0.55 \\
\hline Active cigarette smoker, $\mathrm{n}(\%)$ & $19(27.5)$ & $60(24.8)$ & \\
\hline Ex-smoker, n (\%) & $40(58)$ & $146(60)$ & \\
\hline Pack-years, mean $( \pm S D)$ & $51 \pm 32$ & $50 \pm 33$ & 0.73 \\
\hline Biomass exposure, $\mathrm{n}(\%)$ & $8(11.9)$ & $21(8.9)$ & 0.45 \\
\hline \multicolumn{4}{|l|}{ Long-term home device use before ICU } \\
\hline LTOT, n (\%) & $32(47.8)$ & $165(68.5)$ & 0.002 \\
\hline Long-term domiciliary ventilation, $\mathrm{n}$ (\%) & $17(25.4)$ & $97(40.2)$ & 0.56 \\
\hline \multicolumn{4}{|l|}{ Comorbid diseases } \\
\hline Diabetes mellitus, $\mathrm{n}(\%)$ & $17(24.6)$ & $47(19.3)$ & 0.33 \\
\hline Hypertension, n (\%) & $33(47)$ & $102(41.9)$ & 0.40 \\
\hline Congestive heart failure, $\mathrm{n}(\%)$ & $20(28.9)$ & $76(31.2)$ & 0.71 \\
\hline Ischemic heart disease, $\mathrm{n}(\%)$ & $18(26)$ & $39(16)$ & 0.057 \\
\hline Arrhythmia, n (\%) & $8(11.6)$ & $32(13.2)$ & 0.73 \\
\hline Chronic renal diseases, $\mathrm{n}(\%)$ & $4(5.7)$ & $3(1.2)$ & 0.024 \\
\hline Benign prostatic hyperplasia, n (\%) & $9(13)$ & $30(12.3)$ & 0.87 \\
\hline Chronic neurological disease, $\mathrm{n}(\%)$ & $9(13.1)$ & $22(9.05)$ & 0.32 \\
\hline Obstructive sleep apnea, n (\%) & $3(4.3)$ & $16(6.5)$ & 0.49 \\
\hline Depressive disorders, $\mathrm{n}(\%)$ & $7(10.1)$ & $28(11.5)$ & 0.74 \\
\hline Dementia, $\mathrm{n}(\%)$ & $6(8.6)$ & $14(5.7)$ & 0.33 \\
\hline Malignancy other than lungs, $\mathrm{n}(\%)$ & $\mathrm{I}(\mathrm{I} .4)$ & $6(2.4)$ & 0.61 \\
\hline
\end{tabular}

Notes: Severe acidosis group: $\mathrm{pH} \leq 7.20$; acidotic group: $\mathrm{pH} 7.21-7.34$.

Abbreviations: BMI, body mass index; ICU, intensive care unit; LTOT, long-term oxygen therapy. 
Table 2 ICU data of the study groups

\begin{tabular}{|c|c|c|c|}
\hline & $\begin{array}{l}\text { Severe } \\
\text { acidosis group } \\
(\mathrm{N}=69)\end{array}$ & $\begin{array}{l}\text { Mild-to-moderate } \\
\text { acidosis group } \\
(\mathrm{N}=\mathbf{2 4 3})\end{array}$ & $\overline{p \text {-value }}$ \\
\hline \multicolumn{4}{|l|}{ Reasons for ICU admission, $\mathrm{n}(\%)$} \\
\hline Pneumonia & $27(39.1)$ & $84(34.6)$ & 0.72 \\
\hline Infection of LRT & $28(40.6)$ & $115(47.3)$ & \\
\hline Pulmonary embolism & $0(0)$ & $\mathrm{I}(0.4)$ & \\
\hline Right heart failure & $8(11.6)$ & $18(7.4)$ & \\
\hline Other reasons & $6(8.7)$ & $23(9.5)$ & \\
\hline \multicolumn{4}{|l|}{ Laboratory values on the admission to the ICU } \\
\hline Leukocyte count, $10^{9} \mathrm{~L}$, median (IQR) & $13.6(10.5-17.8)$ & $10.5(8.2-14.6)$ & 0.001 \\
\hline Hemoglobin, g/dL, median (IQR) & $13(||-\mid 4)$ & $13(\mid 1-14)$ & 0.36 \\
\hline Hematocrit, \% ( $\pm S D)$ & $38 \pm 6$ & $39 \pm 7$ & 0.30 \\
\hline Platelet count, $10^{9} \mathrm{~L}$, median (IQR) & $246(198-325)$ & $243(179-306)$ & 0.18 \\
\hline Blood urea nitrogen, mg/dL $( \pm S D)$ & $86 \pm 16$ & $88 \pm 12$ & 0.50 \\
\hline Serum creatinine, mg/dL, median (IQR) & $0.91(0.76-1.4)$ & $0.81(0.66-1.12)$ & 0.007 \\
\hline CRP (mg/dL), median (IQR) & $47(13-124)$ & $37(13-96)$ & 0.52 \\
\hline \multicolumn{4}{|l|}{$A B G$ values on the admission to the ICU } \\
\hline $\mathrm{pH}( \pm \mathrm{SD})$ & $7.15 \pm 0.07$ & $7.29 \pm 0.06$ & 0.001 \\
\hline $\mathrm{PaCO}_{2}, \mathrm{mmHg}( \pm \mathrm{SD})$ & $87 \pm 26$ & $72 \pm 17$ & 0.001 \\
\hline $\mathrm{PaO}_{2} / \mathrm{FiO}_{2}$, median (IQR) & $169(117-272)$ & $175(\mid 33-227)$ & 0.67 \\
\hline $\mathrm{HCO}_{3}, \mathrm{mmol}( \pm \mathrm{SD})$ & $29 \pm 8$ & $33 \pm 8$ & 0.001 \\
\hline $\mathrm{BE}$, median (IQR) & $2(-4$ to 5$)$ & $7(3-12)$ & 0.001 \\
\hline $\mathrm{PaO}_{2} / \mathrm{FiO}_{2}$ ratio $<150, \mathrm{n}(\%)$ & $29(42)$ & $87(35)$ & 0.001 \\
\hline Septic shock, n (\%) & $25(36)$ & $72(29)$ & 0.30 \\
\hline Two organ failures, $n(\%)$ & $39(56.5)$ & $103(42.4)$ & 0.037 \\
\hline GCS (mean) & $11.8 \pm 4.2$ & $14.0 \pm 2.3$ & 0.001 \\
\hline APACHE II score on admission, median (IQR) & $25(20-31)$ & $19(16-24)$ & 0.001 \\
\hline APACHE II predicted mortality $( \pm S D)$ & $53.6 \pm 23.8$ & $36.7 \pm 18.7$ & 0.001 \\
\hline ICU mortality, N (\%) & $9(13.0)$ & $40(16.5)$ & 0.49 \\
\hline Length of ICU stay, days, median (IQR) & $7(5-10)$ & $6(4-9)$ & 0.07 \\
\hline
\end{tabular}

Notes: Severe acidosis group: $\mathrm{pH} \leq 7.20$; acidotic group: $\mathrm{pH} 7.21-7.34$.

Abbreviations: $\mathrm{ABG}$, arterial blood gas; $\mathrm{APACHE}$, acute physiology and chronic health evaluation; $\mathrm{BE}$, base excess; CRP, C-reactive protein; FiO ${ }_{2}$, fraction of inspired oxygen; GCS, Glasgow Coma Scale; ICU, intensive care unit; IQR, interquartile range; LRT, lower respiratory tract infection; PaCO ${ }_{2}$, Partial carbon dioxide pressure; $\mathrm{PaO}_{2}$, partial arterial oxygen pressure.

ICU stay, and mortality. Reasons for ICU admission were similar in both groups. The severely acidotic patients had a higher leukocyte count and significantly higher serum creatinine levels (although clinically nonsignificant) than the mild-to-moderate acidosis group. ABG values (except oxygenation) were significantly worse in the severe acidosis group, and this group had significantly higher APACHE II levels, but both the length of ICU stay and mortality were similar in both groups.

The application of mechanical ventilation and the outcome in both groups are shown in Figure 2. NIMV failure rate was significantly higher in the severe acidosis group compared with the mild-to-moderate acidosis group $(60.7 \%$ and $40 \%$, respectively, $p<0.001)$. Compared with the mild-to-moderate acidosis group, NIMV failure patients had a lower mortality rate in the severe acidosis group $(9.6 \%$ and $37.9 \%$, respectively). In the present study a difference between the mortality of the two groups which were treated with IMV initially was found; the severe acidosis group had a lower mortality (9\%) compared with the mild-to-moderate acidosis group (36.3\%). The reasons for death in the mildto-moderate acidosis group with NIMV failure were as follows: 22 patients had severe sepsis and septic shock; four patients had myocardial infarction (due to coronary artery disease and severe sepsis), five patients had end-stage COPD, and one patient had a massive pulmonary embolism. Septic shock was the main reason for death in the acidotic group with NIMV failure.

Table 3 summarizes ABG values on the day of ICU discharge, short- and long-term mortality rates, and the use of long-term domiciliary NIMV and LTOT and mortality rates for 28 days and 1,2, and 3 years. Both groups had similar $\mathrm{pH}$ values on the day of ICU discharge. $\mathrm{PaCO}_{2}$ was significantly higher in the acidotic group. The prescription 


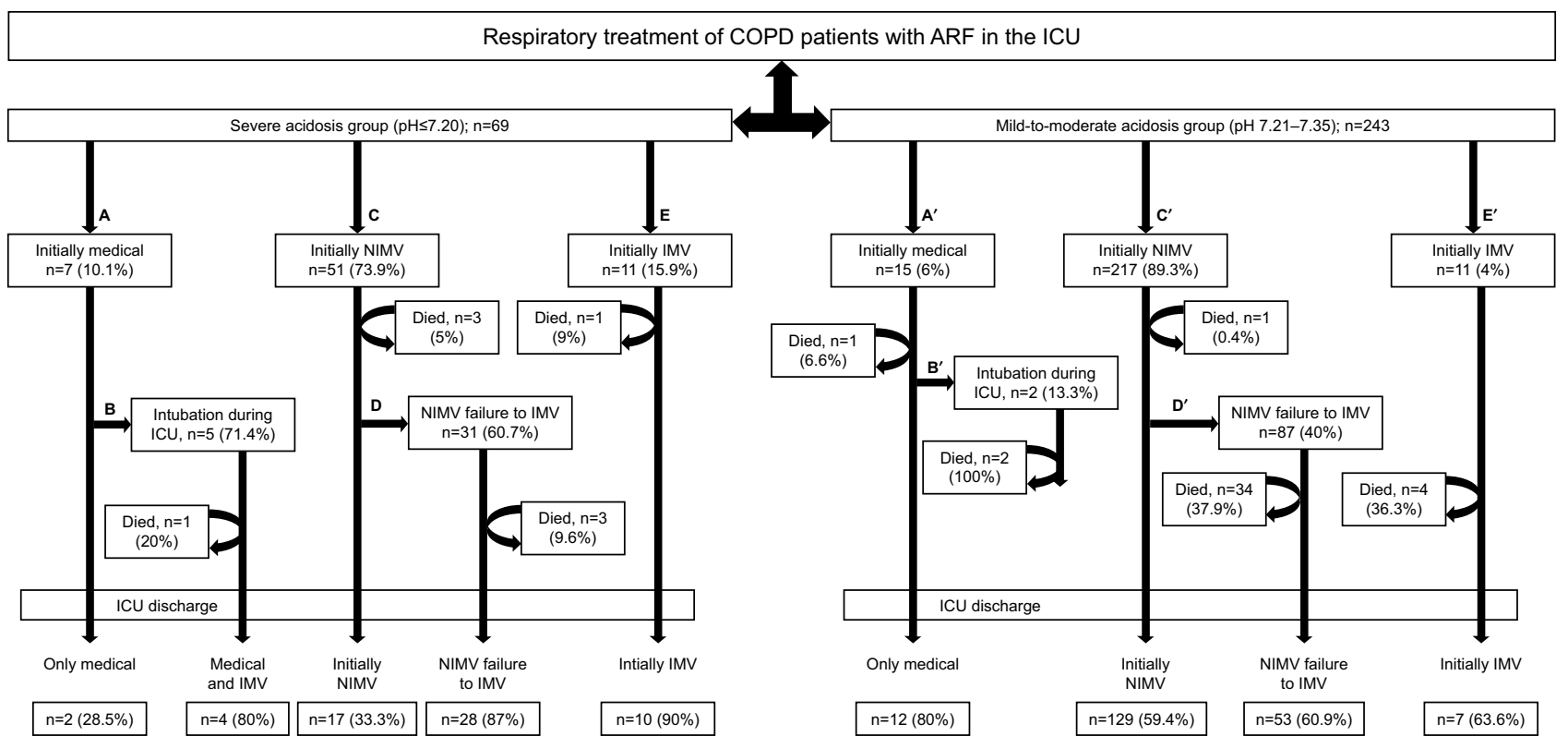

Figure 2 The treatment of COPD patients with ARF in the ICU in the severe and mild-to-moderate acidosis groups.

Notes: (A) Patient group with severe acidosis admitted to the ICU due to ARF, who were followed up with oxygen and medical therapy. (B) Patient group with severe acidosis admitted to the ICU due to ARF, who were extubated during the follow-up with oxygen and medical therapy. (C) Patient group with severe acidosis admitted to the ICU due to ARF, who were applied NIMV. (D) Patient group with severe acidosis admitted to the ICU due to ARF, who were extubated because of NIMV failure. (E) Patient group with severe acidosis admitted to the ICU due to ARF, who were extubated at the time of ICU admission. ( $\mathbf{A}^{\prime}$ ) Patient group with mild-to-moderate acidosis admitted to the ICU due to ARF, who were followed up with oxygen and medical therapy. (B') Patient group with mild-to-moderate acidosis admitted to the ICU due to ARF, who were extubated during the follow-up with oxygen and medical therapy. ( $\mathbf{C}^{\prime}$ ) Patient group with mild-to-moderate acidosis admitted to the ICU due to ARF, who were applied NIMV. (D') Patient group with mild-to-moderate acidosis admitted to the ICU due to ARF, who were extubated because of NIMV failure. (E') Patient group with mild-to-moderate acidosis admitted to the ICU due to ARF, who were extubated at the time of ICU admission. The significance of comparison of mortality was as follows: $A-A^{\prime} p>0.053, B-B^{\prime} p<0.001, C-C^{\prime} p<0.001, D-D^{\prime} p<0.010$, and $E-E^{\prime} p<0.038$.

Abbreviations: ARF, acute respiratory failure; ICU, intensive care unit; IMV, invasive mechanical ventilation; NIMV, noninvasive mechanical ventilation.

Table 3 Data of the study groups on the day of ICU discharge and follow-up period

\begin{tabular}{|c|c|c|c|}
\hline & $\begin{array}{l}\text { Severe } \\
\text { acidosis } \\
\text { group } \\
(\mathbf{N}=61)\end{array}$ & $\begin{array}{l}\text { Mild-to- } \\
\text { moderate } \\
\text { acidosis group } \\
(\mathrm{N}=\mathbf{2 0 1})\end{array}$ & p-value \\
\hline \multicolumn{4}{|c|}{ ABG values on the day of ICU discharge } \\
\hline $\mathrm{pH}( \pm \mathrm{SD})$ & $7.4 I \pm 0.04$ & $7.40 \pm 0.04$ & 0.10 \\
\hline $\mathrm{PaCO}_{2}, \mathrm{mmHg}( \pm \mathrm{SD})$ & $50 \pm 10$ & $59 \pm 34$ & 0.001 \\
\hline $\mathrm{PaO}_{2} / \mathrm{FiO}_{2}( \pm \mathrm{SD})$ & $288 \pm 95$ & $272 \pm 111$ & 0.27 \\
\hline $\mathrm{HCO}_{3}, \mathrm{mmol}( \pm \mathrm{SD})$ & $33 \pm 9$ & $34 \pm 5$ & 0.49 \\
\hline \multicolumn{4}{|c|}{ History of long-term device use on the day of ICU admission } \\
\hline Domiciliary LTOT, n (\%) & $24(39.3)$ & I $44(72.4)$ & $<0.00 \mathrm{I}$ \\
\hline Domiciliary NIMV, n (\%) & $15(24.6)$ & $90(45.2)$ & 0.005 \\
\hline \multicolumn{4}{|c|}{ Long-term device use when discharged from ICU } \\
\hline Domiciliary LTOT, n (\%) & $43(70.5)$ & $177(88.1)$ & $<0.001$ \\
\hline Domiciliary NIMV, n (\%) & $33(54.1)$ & $154(76.6)$ & $<0.001$ \\
\hline \multicolumn{4}{|l|}{ Mortality rates, n (\%) } \\
\hline 28th day & 13.1 (8) & $11.9(24)$ & 0.81 \\
\hline First year & $27.9(17)$ & $38.8(123)$ & 0.12 \\
\hline Second year & 54.1 (33) & $52.2(105)$ & 0.80 \\
\hline Third year & $62.3(38)$ & $63.7(128)$ & 0.84 \\
\hline
\end{tabular}

Abbreviations: $\mathrm{ABG}$, arterial blood gas; $\mathrm{FiO}_{2}$, fraction of inspired oxygen; ICU, intensive care unit; LTOT, long-term oxygen therapy; NIMV, noninvasive mechanical ventilation; $\mathrm{PaCO}_{2}$, partial carbon dioxide pressure; $\mathrm{PaO}_{2}$, partial arterial oxygen pressure. of domiciliary NIMV devices was significantly higher in the mild-to-moderate acidosis group.

Figure 3 shows the Kaplan-Meier cumulative survival curves for the severely acidotic and mild-to-moderate acidotic COPD patients after ICU discharge. Both groups had similar survival rates. The reasons for long-term mortality were not recorded due to the absence of electronic data.

Table 4 summarizes the comparison of survivors and non-survivors of COPD patients with ARF in the ICU. The main differences in non-survivors were older age, less number of domiciliary NIMV usage, and higher rates of smoking history and with much more severe ICU data.

Table 5 summarizes the logistic regression analysis of patients' data according to the included parameters in the model.

Table 6 summarizes the Cox regression analysis for long-term mortality predictors in COPD patients after ICU discharge. Cox regression analysis showed the HR of 28-day, 1-, 2-, 3-year mortality in all patients after ICU discharge. The presence of older age and $\mathrm{PaO}_{2} / \mathrm{FiO}_{2}$ of $<300 \mathrm{mmHg}$ were found to be significant short- and long-term mortality risk factors, respectively, and by the 28th day the mortality 


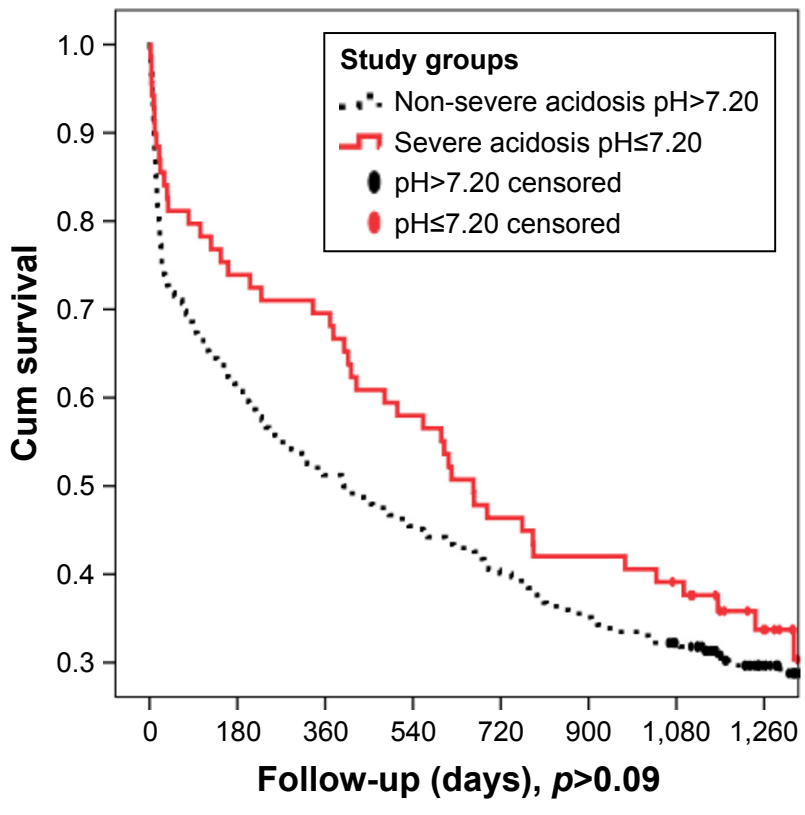

Figure 3 Survival functions of COPD with severe and mild-to-moderate acidosis.

had also affected intropic use in the ICU and presence of severe acidosis. The presence of $\mathrm{pH} \leq 7.20$ had significant high-risk mortality in the 28-day and 1-year follow-up period. Age, body mass index $(\mathrm{BMI}) \leq 20 \mathrm{~kg} / \mathrm{m}^{2}$, and $\mathrm{PaO}_{2} /$ $\mathrm{FiO}_{2}<300$ were found to be significant high-risk predictors of mortality at $2-3$ years.

Kaplan-Meier survival curves showed similar longterm survival in COPD patients with/without LTOT use ( $p=0.26$; Figure 4A). Further, sub-Kaplan-Meier analysis was performed for those patients who had severe and mild-tomoderate acidosis during ICU stay with/without LTOT after ICU discharge. Mild-to-moderate acidotic COPD patients using LTOT had longer survival after ICU discharge than those without LTOT in the Kaplan-Meier survival curves (Figure 4B). On the other hand, severely acidotic COPD patients with LTOT showed shorter survival than those without LTOT (Figure 4C).

\section{Discussion}

The main finding of this study was that the overall mortality was similar in both groups. However, COPD patients with acute-on-chronic hypoxemic respiratory failure using LTOT, with severe acidosis $(\mathrm{pH} \leq 7.20)$, in the ICU showed shorter survival time at the 3-year follow-up than mild-to-moderate acidotic COPD patients $(\mathrm{pH}>7.20$ and $<7.35)$ who did not use LTOT after ICU discharge (Figure 4A-C). Kaplan-Meier cumulative survival analysis showed that the 28-day, and 1-, 2 -, and 3-year mortality was $12.2 \%, 36.2 \%, 52.6 \%, 63.3 \%$,
Table 4 The comparison of survivors and non-survivors in COPD patients with ARF in the ICU

\begin{tabular}{|c|c|c|c|}
\hline Variables & Survivor & Non-survivor & $p$-value \\
\hline Number & 262 & 69 & - \\
\hline Gender, male, n (\%) & 78 (204) & $76(38)$ & 0.77 \\
\hline Age, years & $68(61-75)$ & $77(72-8 I)$ & $<0.001$ \\
\hline $\mathrm{BMI} \leq 20 \mathrm{~kg} / \mathrm{m}^{2}, \mathrm{n}(\%)$ & $62(25)$ & $14(29)$ & 0.54 \\
\hline LTOT use, n (\%) & $169(65)$ & $30(60)$ & 0.50 \\
\hline Domiciliary NIMV use, n (\%) & $106(40)$ & II (22) & $<0.001$ \\
\hline \multicolumn{4}{|l|}{ Smoking history } \\
\hline Current smoker & $77(30)$ & $2(4)$ & $<0.001$ \\
\hline Ex-smoker & $145(56)$ & $41(82)$ & \\
\hline Nonsmoker & $39(15)$ & $7(14)$ & \\
\hline $\mathrm{pH} \leq 7.20$ & $61(23)$ & $8(16)$ & 0.26 \\
\hline \multicolumn{4}{|l|}{ Comorbid diseases, n (\%) } \\
\hline Hypertension & $110(42)$ & $24(48)$ & 0.44 \\
\hline Diabetes & $56(2 I)$ & $8(16)$ & 0.39 \\
\hline Congestive heart failure & $74(28)$ & $22(44)$ & 0.027 \\
\hline Chronic renal failure & $5(2)$ & $2(4)$ & 0.36 \\
\hline Coronary heart diseases & $47(18)$ & $9(18)$ & 0.99 \\
\hline Arrhythmia & $31(12)$ & $9(18)$ & 0.23 \\
\hline \multicolumn{4}{|l|}{ ICU data } \\
\hline $\mathrm{PaO}_{2} / \mathrm{FiO}_{2}<300$ & $97(38)$ & $19(38)$ & 0.94 \\
\hline IMV, n (\%) & $102(39)$ & $45(90)$ & $<0.001$ \\
\hline NIMV, n (\%) & $239(91)$ & $44(88)$ & 0.47 \\
\hline Septic shock, n (\%) & $78(30)$ & $45(90)$ & $<0.001$ \\
\hline Two organ failures, n (\%) & $12(5)$ & $28(56)$ & $<0.001$ \\
\hline Resistant pathogen, n (\%) & $26(10)$ & $22(44)$ & $<0.001$ \\
\hline Use of two antibiotics, n (\%) & 127 (49) & $38(76)$ & $<0.001$ \\
\hline Use of three antibiotics, n (\%) & $12(5)$ & $17(34)$ & $<0.001$ \\
\hline Antifungal use, $n(\%)$ & $13(5)$ & II (22) & $<0.001$ \\
\hline Length of ICU stay, days & $6(4-8)$ & $9(5-15)$ & 0.001 \\
\hline
\end{tabular}

Abbreviations: ARF, acute respiratory failure; BMI, body mass index; ICU, intensive care unit; IMV, invasive mechanical ventilation; LTOT, long-term oxygen therapy; NIMV, noninvasive mechanical ventilation; $\mathrm{PaO}_{2} / \mathrm{FiO}_{2}$, partial arterial oxygen pressure to fractional inspired oxygen.

Table 5 ICU mortality risk factors for COPD with ARF

\begin{tabular}{|c|c|c|c|c|}
\hline \multirow[t]{2}{*}{ Variables } & \multirow{2}{*}{$\begin{array}{l}\text { Odds } \\
\text { ratio }\end{array}$} & \multicolumn{2}{|l|}{ Cl } & \multirow[t]{2}{*}{$p$-value } \\
\hline & & Lower & Upper & \\
\hline Application of IMV in the ICU & 0.03 & 5.42 & 36.75 & $<0.001$ \\
\hline Age, for each year & 1.17 & 1.10 & 1.25 & $<0.001$ \\
\hline $\mathrm{pH} \leq 7.20$ & 0.17 & 0.05 & 0.56 & 0.003 \\
\hline Presence of resistant pathogen & 5.88 & $1.6 \mathrm{I}$ & 21.38 & 0.007 \\
\hline Presence of two organ failures & 6.07 & 1.50 & 24.61 & 0.012 \\
\hline Chronic renal failure & 22.58 & 1.99 & 256.84 & 0.012 \\
\hline Application of NIMV in the ICU & 0.24 & 0.06 & 1.00 & 0.049 \\
\hline Coronary arterial diseases & 0.45 & 0.13 & 1.51 & 0.20 \\
\hline $\mathrm{BMI} \leq 20 \mathrm{~kg} / \mathrm{m}^{2}$ & 0.56 & 0.19 & 1.65 & 0.29 \\
\hline $\mathrm{PaO}_{2} / \mathrm{FiO}_{2}<300$ & 1.95 & 0.52 & 7.31 & 0.33 \\
\hline ICU days, per each day & 0.98 & 0.91 & 1.06 & 0.62 \\
\hline Presence of sepsis & 1.60 & 0.11 & 22.37 & 0.73 \\
\hline Platelet counts $<100,000$ cell counts $/ \mathrm{L}$ & 0.72 & 0.10 & 5.10 & 0.74 \\
\hline
\end{tabular}

Abbreviations: ARF, acute respiratory failure; BMI, body mass index; ICU, intensive care unit; IMV, invasive mechanical ventilation; NIMV, noninvasive mechanical ventilation; $\mathrm{PaO}_{2} / \mathrm{FiO}_{2}$, partial arterial oxygen pressure to fractional inspired oxygen. 
Table 6 Cox regression analysis for short- and long-term mortality predictors in COPD patients after ICU discharge

\begin{tabular}{|c|c|c|c|c|}
\hline & \multirow[t]{2}{*}{ HR } & \multicolumn{2}{|l|}{$95 \% \mathrm{Cl}$} & \multirow[t]{2}{*}{$p$-value } \\
\hline & & $\begin{array}{l}\text { Lower } \\
\text { limit }\end{array}$ & $\begin{array}{l}\text { Upper } \\
\text { limit }\end{array}$ & \\
\hline \multicolumn{5}{|l|}{ 28th day } \\
\hline Age, years & 1.14 & 1.08 & 1.22 & 0.000 \\
\hline Intropic use in the ICU & 3.31 & 1.28 & 8.60 & 0.014 \\
\hline $\mathrm{PaO}_{2} / \mathrm{FiO}_{2}<300$ & 2.32 & 1.01 & 5.34 & 0.047 \\
\hline $\mathrm{pH} \leq 7.20$ & 0.31 & 0.10 & 1.04 & 0.058 \\
\hline \multicolumn{5}{|l|}{ First year } \\
\hline Age, years & 1.07 & 1.04 & 1.10 & $<0.00 \mathrm{I}$ \\
\hline $\mathrm{pH} \leq 7.20$ & 0.52 & 0.28 & 0.95 & 0.034 \\
\hline $\mathrm{PaO}_{2} / \mathrm{FiO}_{2}<300$ & 1.59 & 1.02 & 2.48 & 0.040 \\
\hline $\mathrm{BMI} \leq 20 \mathrm{~kg} / \mathrm{m}^{2}$ & 1.72 & 1.02 & 2.91 & 0.044 \\
\hline \multicolumn{5}{|l|}{ Second year } \\
\hline Age, years & 1.06 & 1.03 & 1.08 & $<0.000$ \\
\hline $\mathrm{BMI} \leq 20 \mathrm{~kg} / \mathrm{m}^{2}$ & 1.74 & 1.11 & 2.73 & 0.015 \\
\hline $\mathrm{PaO}_{2} / \mathrm{FiO}_{2}<300$ & 1.46 & 1.01 & 2.11 & 0.047 \\
\hline \multicolumn{5}{|l|}{ Third year } \\
\hline Age, years & 1.06 & 1.03 & 1.08 & $<0.001$ \\
\hline $\mathrm{BMI} \leq 20 \mathrm{~kg} / \mathrm{m}^{2}$ & 1.56 & 1.03 & 2.34 & 0.034 \\
\hline $\mathrm{PaO}_{2} / \mathrm{FiO}_{2}<300$ & 1.41 & 1.01 & 1.97 & 0.047 \\
\hline
\end{tabular}

Notes: Cox regression model included the following: age, study group $(\mathrm{pH}<7.2 \mathrm{I}$, $\mathrm{BMI}<2 \mathrm{I} \mathrm{kg} / \mathrm{m}^{2}, \mathrm{PaO}_{2} / \mathrm{FiO}_{2}<300$ ), male gender, comorbidities (diabetes mellitus, hypertension, chronic renal failure disease, coronary artery disease, congestive heart failure, days stay in the ICU, presence of septic shock, presence of resistant pathogen, use of domiciliary device [LTOT, NIMV]); only statistically significant $(p<0.05)$ parameters are shown in the regression analysis.

Abbreviations: BMI, body mass index; HR, hazard ratio; ICU, intensive care unit; LTOT, long-term oxygen therapy; NIMV, noninvasive mechanical ventilation; $\mathrm{PaO}_{2} / \mathrm{FiO}_{2}$, partial arterial oxygen pressure to fractional inspired oxygen.

respectively. Mortality predictors in the short and long term were the presence of $\mathrm{PaO}_{2} / \mathrm{FiO}_{2}<300, \mathrm{BMI}<21 \mathrm{~kg} / \mathrm{m}^{2}$, and being an older patient in the study population after ICU discharge. However, mortality was higher in the severe acidosis group at day 28 and at 1-year follow-up period.

\section{Acute ICU setting}

Studies show that when renal failure occurs in COPD patients, the compensatory role of the kidney in respiratory acidosis may be less effective with reduced titratable acidity production and with a consequent smaller increase in serum bicarbonate and more severe acidosis. ${ }^{6,8}$ In the current study, patients with chronic renal failure were $<5 \%$ in each group. During the ICU stay, there was a significantly higher percentage of acute renal failure (serum creatinine $>2 \mathrm{mg} / \mathrm{dL}$ ), due to severe sepsis, in the severe acidosis group than in the mild-to-moderate acidosis group (5\% vs $13 \%$ ); however, the requirement for dialysis was only observed in the acidotic group ( $\mathrm{n}=6)$.

One could make the assumption that COPD patients admitted to hospital with severe acidotic respiratory failure would comprise a higher percentage of patients undergoing LTOT. However, in the current study, very severely acidotic COPD patients had a significantly lower rate of LTOT usage. This may be explained by a number of reasons; First, those patients using LTOT are followed closely and may be more aware of their symptoms and severity; Second, the flow of oxygen may prevent hypoventilation, and this could prevent severe hypercapnia; Third, severe acidosis could be a reason for severe sepsis. Previous studies have shown that the requirement for ICU in COPD patients with ARF was due to infectious origins..$^{20,21}$ In the current study, nearly one-third of both groups had infectious reasons for ARF, independent of the severity of acidosis. However, blood leukocyte counts and APACHE II scores were significantly higher in the severely acidotic patients.

In the past decade, Confalonieri et $\mathrm{al}^{5}$ presented a chart of failure risk for NIMV in patients with COPD and showed that a pH of $<7.25$, a GCS of $<11$, a respiratory rate higher than 30/minute, and an APACHE II score higher than 29 have a predicted NIMV failure risk greater than $70 \%$. The same study showed that after a 2-hour NIMV application, having a $\mathrm{pH}$ that was persistently lower than 7.25 increased the risk of NIMV failure to $>90 \%$. In the current study, although we investigated lower $\mathrm{pH}$ in terms of risk for mortality, the majority of patients had initial NIMV, and even in the severe acidosis group, NIMV failure rate was less than one-third. During the past decade, increased NIMV familiarity and more experienced staff have resulted in NIMV being applied more safely in the ICU. Very recently, Masa et al ${ }^{22}$ studied 969 patients (COPD; 540, obesity hypoventilation syndrome; 189 , acute cardiogenic pulmonary edema; 240) with ARF requiring NIMV in the ICU, and for the evaluation of NIMV success, patients were grouped according to $\mathrm{pH}<7.25$ value. They found that NIMV could be successfully applied to patients with ARF and with different diseases even when the $\mathrm{pH}$ was $<7.25$ in the ICU (COPD 93\%). ${ }^{22}$ In the current study, the groups were stratified relative to $\mathrm{pH} 7.20$, and NIMV success was achieved in nearly one-third of the severe acidosis group vs two-thirds of the mild-to-moderate acidosis group (Figure 2). In a meta-analysis that included 14 studies and evaluated 979 hospitalized COPD patients, the intubation rate ranged from $9 \%$ to $56 \%$ in COPD patients with initial NIMV treatment (mean intubation rate was 35\%). The relative risk of mortality was $13 \%-100 \%$, and with an average of nearly $45 \% .{ }^{23}$ Mortality as a result of COPD exacerbation with ARF requiring the ICU depended on the need for IMV (average mortality 45\%). In the current study, NIMV failure rates in the severe and mild-to-moderate acidosis groups had a similar range to that presented in this meta-analysis; however, ICU mortality rates for both groups were less than average 

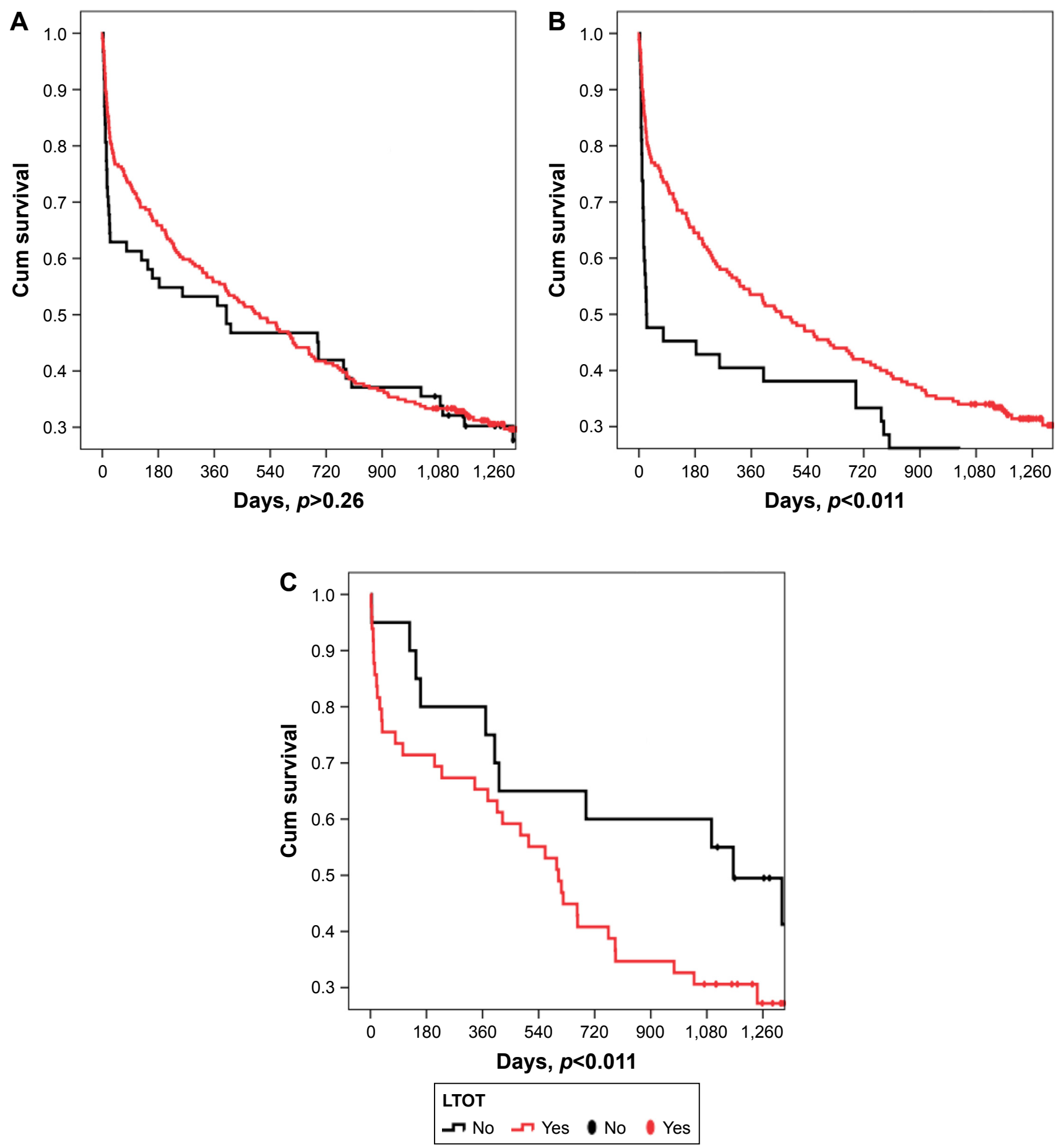

Figure 4 Survival functions of discharged COPD patients in long term follow-up according to severity of acidosis and LTOT use.

Notes: (A) Survival functions of COPD after discharge from hospital. (B) Survival functions of COPD patients with $\mathrm{pH}>7.20$ group. (C) Survival functions of COPD patients in the $\mathrm{pH}<7.20$ group.

Abbreviation: LTOT, long-term oxygen therapy.

according to the meta analysis. Furthermore, the mortality rates were nearly a half and one-quarter of the predicted mortality rates according to APACHE II scores in the mild-to-moderate and severe acidosis groups, respectively (Figure 2). Very recently, European Respiratory Society/American Thoracic
Society published the clinical practice guidelines for NIMV due to ARF. ${ }^{24}$ This guideline stated that COPD patients with a pH between 7.25 and 7.35 and without metabolic acidosis can manage with NIMV, and the response to NIMV should be followed closely (1-4 hours). ${ }^{24}$ 


\section{Short- and long-term follow-up}

In the current study in the short term (28-day), survival analysis showed that in older patients the intropic therapy due to septic shock together with $\mathrm{PaO}_{2} / \mathrm{FiO}_{2}<300$ had an increased risk of mortality. However, severely acidotic patients' survival rate was higher, nearly $70 \%$ compared to the mild-tomoderate acidotic COPD patients in the ICU. In the study, our findings about survival rate in the severe acidosis group did not correlate with our hypothesis. These short term findings can be explained as the usage of inotropic medication for severe respiratory failure due to hypoxemia were much more important for short term survival after discharge from ICU in COPD patients. Meanwhile, severely acidotic patients due to hypercapnic respiratory failure without intropic requirement can be treated by mechanical ventilation in the ICU, and those patients who were discharged from the ICU did not have any further risk of short and 1-year follow-up period mortality.

The current study demonstrated that severe acidosis did not affect long-term survival (Figure 3). Khilnani et a ${ }^{25}$ studied 1-year survival of COPD patients with severe acidosis after ICU admission (median $\mathrm{pH}$ was 7.25, minimum 6.87, maximum 7.44). They found similar $\mathrm{pH}$ values in both the survivors and non-survivors during the follow-up period. They defined the risk factors for long-term survival as follows: admission APACHE II score, 13.5, and after 24 hours, of serum albumin, $3.05 \mathrm{~g} / \mathrm{dL}$. They demonstrated that $\mathrm{PaCO}_{2}$ and $\mathrm{HCO}_{3}$ values did not affect mortality risk factors.

In the current study, a significantly higher number of moderate acidotic patients used LTOT after ICU discharge than severely acidotic patients. It can be assumed that, in the severe acidosis group since the acidosis depends on the severity of sepsis, the previous stable clinical condition was observed after ICU discharge. Besides, depending on the severity of the existing COPD, patients were discharged with LTOT in the mild-to-moderate acidosis group. In addition, also our long-term survival analysis performed by Cox regression analysis showed that ICU hypoxemia $\left(\mathrm{PaO}_{2} / \mathrm{FiO}_{2}<300\right)$, elderly patients, and lean COPD patients $\left(\mathrm{BMI}<21 \mathrm{~kg} / \mathrm{m}^{2}\right)$ were factors which decreased long-term survival. The objective of this study was to clarify the damage of severe acidosis in tissue and to further establish the negative effect of severe acidosis on long-term survival. We also showed that severely acidotic patients with a requirement for LTOT had significantly shorter survival times after ICU discharge than those without a requirement for LTOT. This may be explained by the tissue damage due to severe acidosis that does not respond to oxygen treatment (Figure 4B).
If the acidosis is not very severe, tissue damage may be reversible and may respond to the LTOT, leading to increased long-term survival (Figure 4C). Recently, the Long-Term Oxygen Treatment Trial (LOTT) research group published a study in which the supplemental oxygen group of patients with COPD was prescribed 24-hour oxygen, if their resting $\mathrm{SpO}_{2}$ was $89 \%-93 \%$ and they were given oxygen only during sleep and exercise, if they desaturated during exercise. The protocol specified that patients in the supplemental oxygen group continued the use of supplemental oxygen regardless of any increase in the $\mathrm{SpO}_{2}$ level and that patients in the non-supplemental oxygen group avoided the use of supplemental oxygen unless they exhibited severe resting desaturation $\left(\mathrm{SpO}_{2} \leq 88 \%\right)$ or severe exercise-induced desaturation $\left(\mathrm{SpO}_{2}<80 \%\right.$ for $\geq 1$ minute). If either of these conditions developed, oxygen was prescribed, and the oxygen requirement was reassessed after 30 days. ${ }^{26}$ In the current study, COPD patients with chronic respiratory failure had more severe resting desaturation than the LOTT research group patients. Patients in the LOTT research group with similar desaturation levels were prescribed oxygen.

In the current study, due to analysis, no significant difference was determined in domiciliary NIMV both for 1 month and 1 year survival (Table 6). Long-term NIMV usage may prolong survival, although the quality-of-life improvement was questionable according to the international guidelines. ${ }^{4}$

BMI is a component of BODE (body mass index, air flow obstruction, Dyspmea, exercise) score, and long-term survival was decreased if $\mathrm{BMI}<21 \mathrm{~kg} / \mathrm{m}^{2} .^{10}$ In the current study, $\mathrm{BMI}<21 \mathrm{~kg} / \mathrm{m}^{2}$ showed decreased long-term survival in the 1-3-year follow-up period; except at day 28.

\section{Limitations}

There were some limitations in the current study. First, it was performed at a single center, although the sample size was sufficient to indicate the clinical implications for COPD patients. Second, it was a retrospective study, although all patient data were recorded each day by the same ICU team. Third, the spirometry data were not recorded because of the absence of an electronic database; however, all COPD diagnoses were made by pulmonary specialists within a teaching hospital for chest diseases and with the help of spirometry values.

\section{Conclusion}

The primary finding of this study was that the overall mortality was similar in both groups. However, COPD patients with severe acidosis who were admitted to the ICU and using 
LTOT after ICU discharge had significantly shorter survival time. COPD patients with chronic hypoxemia and exposure to severe acidosis in the ICU do not benefit from LTOT after ICU discharge compared with COPD patients who had severe acidosis not requiring LTOT.

This can be explained by the presence of severe acidosis, which causes further harmful effects on hemodynamics and metabolism in hypoxemic patients with COPD. Although the current study showed that severe acidotic and mild-tomoderate acidotic COPD patients had similar long-term survival, the presence of intropic use during the ICU stay and having acute hypoxemia in the ICU $\left(\mathrm{PaO}_{2} / \mathrm{FiO}_{2}<300\right)$ increased short-term mortality nearly two to three times. Our findings indicate that half of COPD patients can survive for 1 year and one-third of COPD patients can survive for 3 years after ICU discharge following acute exacerbation. To further increase these short survival rates, physicians should closely followup patients who are prescribed LTOT with severe acidosis and intropic requirement in the ICU. To increase long-term survival after ICU discharge, physicians should also evaluate elder and lean COPD patients carefully.

\section{Acknowledgments}

The authors thank Gokay Gungor, Ozlem Yazicioglu Mocin, Huriye Berk Takir, Cuneyt Salturk, and Nezihe Ciftaslan Goksenoglu for providing support for this study and Sharon Forsyth for editing the manuscript. The English in this document has been checked by at least two professional editors; both are native speakers of English (http://www. biomedicalediting.com). The manuscript has been read and approved by all the authors, and each author believes that the manuscript represents honest work.

\section{Author contributions}

All the authors have made substantial contributions to conception and design, or acquisition of data, or analysis and interpretation of data; they have been involved in drafting the manuscript or revising it critically for important intellectual content; and they approved the final version of the manuscript. SG contributed to conception and design, acquisition, analysis, interpretation of data, and drafting the submitted article and provided final approval of the version to be published. FK contributed to conception, interpretation of data, and critical revision of the submitted article for important intellectual content and provided final approval of the version to be published. II contributed to analysis, interpretation of data and provided final approval of the version to be published. FC contributed to conception, interpretation of data and provided final approval of the version to be published. ET contributed to conception, design, and critical revision of the submitted article for important intellectual content and provided final approval of the version to be published. PAG contributed to conception and interpretation of data and provided final approval of the version to be published. EA contributed to conception, design, analysis, and critical revision of the submitted article for important intellectual content and provided final approval of the version to be published. BO contributed to conception, design, interpretation of data, and critical revision of the submitted article for important intellectual content and provided final approval of the version to be published. NA contributed to conception, design, interpretation of data, and critical revision of the submitted article for important intellectual content and provided final approval of the version to be published. ZK contributed to analysis, interpretation of data, and critical revision of the submitted article for important intellectual content and provided final approval of the version to be published.

\section{Disclosure}

All the authors who contributed to the study do not have any industry relationships for the past 2 years. The authors report no other conflicts of interest in this work.

\section{References}

1. Anand IS, Chandrashekhar Y, Ferrari R, et al. Pathogenesis of congestive state in chronic obstructive pulmonary disease. Studies of body water and sodium, renal function, hemodynamics, and plasma hormones during edema and after recovery. Circulation. 1992;86(1):12-21.

2. Jeffrey AA, Warren PM, Flenley DC. Acute hypercapnic respiratory failure in patients with chronic obstructive lung disease: risk factors and use of guidelines for management. Thorax. 1992;47(1):34-40.

3. Warren PM, Flenley DC, Millar JS, Avery A. Respiratory failure revisited: acute exacerbations of chronic bronchitis between 1961-1968 and 1970-1976. Lancet. 1980;1(8166):467-470.

4. Global Initiative for Chronic Obstructive Lung Disease [homepage on the Internet]. Global Strategy for Diagnosis, Management and Prevention of COPD. 2012. Available from: http://www.goldcopd.org. Accessed October 8, 2012.

5. Confalonieri M, Garuti G, Cattaruzza MS, et al. Italian noninvasive positive pressure ventilation (NPPV) study group. A chart of failure risk for noninvasive ventilation in patients with COPD exacerbation. Eur Respir J. 2005;25(2):348-355.

6. Incalzi RA, Corsonello A, Pedone C, et al; Extrapulmonary Consequences of COPD in the Elderly Study Investigators. Chronic renal failure: a neglected comorbidity of COPD. Chest. 2010;137(4):831-837.

7. Van Gestel YR, Chonchol M, Hoeks SE, et al. Association between chronic obstructive pulmonary disease and chronic kidney disease in vascular surgery patients. Nephrol Dial Transplant. 2009;24(9): 2763-2767.

8. Terzano C, Conti V, Di Stefano F, et al. Comorbidity, hospitalization, and mortality in COPD: results from a longitudinal study. Lung. 2010; 188(4):321-329.

9. Bruno CM, Valenti M. Acid-base disorders in patients with chronic obstructive pulmonary disease: a pathophysiological review. J Biomed Biotechnol. 2012;2012:915150. 
10. Celli BR, Cote CG, Marin JM, et al. The body-mass index, airflow obstruction, dyspnea, and exercise capacity index in chronic obstructive pulmonary disease. $N$ Engl J Med. 2004;350(10):1005-1012.

11. Ambrosino N, Vagheggini G. Non-invasive ventilation in exacerbations of COPD. Int J Chron Obstruct Pulmon Dis. 2007;2(4):471-476.

12. Nava $\mathrm{S}$, Hill N. Non-invasive ventilation in acute respiratory failure. Lancet. 2009;374(9685):250-259.

13. Bone RC, Balk RA, Cerra FB, et al. Definitions for sepsis and organ failure and guidelines for the use of innovative therapies in sepsis. The ACCP/SCCM Consensus Conference Committee. American College of Chest Physicians/Society of Critical Care Medicine. Chest. 1992;101: 1644-1655.

14. Kaukonen KM, Bailey M, Pilcher D, Cooper DJ, Bellomo R. Systemic inflammatory response syndrome criteria in defining severe sepsis. N Engl J Med. 2015;372:1629-1638.

15. Anthonisen NR, Manfreda J, Warren CP, Hershfield ES, Harding GK, Nelson NA. Antibiotic therapy in exacerbations of chronic obstructive pulmonary disease. Ann Intern Med. 1987;106(2):196-204.

16. Mandell LA, Wunderink RG, Anzueto A, et al. Infectious Diseases Society of America/American Thoracic Society consensus guidelines on the management of community-acquired pneumonia in adults. Clin Infect Dis. 2007;44(suppl 2):S27-S72.

17. Knaus WA, Draper EA, Wagner DP, Zimmerman JE. APACHE II: a severity of disease classification system. Crit Care Med. 1985;13(10): 818-829.

18. Clinical indications for noninvasive positive pressure ventilation in chronic respiratory failure due to restrictive lung disease, COPD, and nocturnal hypoventilation - a consensus conference report. Chest. 1999; 116(2):521-534
19. Sessler CN, Gosnell MS, Grap MJ, et al. The Richmond AgitationSedation Scale: validity and reliability in adult intensive care unit patients. Am J Respir Crit Care Med. 2002;166(10):1338-1344.

20. Ongel EA, Karakurt Z, Salturk C, et al. How do COPD comorbidities affect ICU outcomes? Int J Chron Obstruct Pulmon Dis. 2014;9: 1187-1196.

21. Fagon JY, Chastre J. Severe exacerbations of COPD patients: the role of pulmonary infections. Semin Respir Infect. 1996;11(2):109-118.

22. Masa JF, Ultrabo I, Terreros JG, et al. Noninvasive ventilation for severely acidotic patients in respiratory intermediate care units. Precision medicine in intermediate care units. BMC Pulm Med. 2016;16(1):97.

23. Quon BS, Gan WQ, Sin DD. Contemporary management of acute exacerbations of COPD: a systematic review and metaanalysis. Chest. 2008;133(3):756-766.

24. Rochwerg B, Brochard L, Elliott MW, et al. Official ERS/ATS clinical practice guidelines: noninvasive ventilation for acute respiratory failure. Eur Respir J. 2017;50:1602426.

25. Khilnani GC, Banga A, Sharma SK. Predictors of mortality of patients with acute respiratory failure secondary to chronic obstructive pulmonary disease admitted to an intensive care unit: a one year study. BMC Pulm Med. 2004;4:12.

26. The Long-Term Oxygen Treatment Trial Research Group. A randomized trial of long-term oxygen for COPD with moderate desaturation. N Engl J Med. 2016;375(17):1617-1627.
International Journal of COPD

\section{Publish your work in this journal}

The International Journal of COPD is an international, peer-reviewed journal of therapeutics and pharmacology focusing on concise rapid reporting of clinical studies and reviews in COPD. Special focus is given to the pathophysiological processes underlying the disease, intervention programs, patient focused education, and self management protocols.

\section{Dovepress}

This journal is indexed on PubMed Central, MedLine and CAS. The manuscript management system is completely online and includes a very quick and fair peer-review system, which is all easy to use. Visit http://www.dovepress.com/testimonials.php to read real quotes from published authors. 